\title{
Palang Pintu Kereta Api Pneumatik Otomatis Berbasis PLC Omron CP1E-NA20DR-A
}

\author{
Ari Widodo', Wahyu Sapto Aji ${ }^{2}$ \\ ${ }^{1}$ Mahasiswa Program Studi Teknik Elektro, Universitas Ahmad Dahlan, Indonesia \\ ${ }^{2}$ Dosen Program Studi Teknik Elektro, Universitas Ahmad Dahlan, Indonesia
}

\section{INFORMASI ARTIKEL \\ Riwayat Artikel: \\ Dikirimkan 26 Agustus 2019, Direvisi 08 September 2019, Diterima 10 September 2019.}

\section{Kata Kunci: \\ Palang Pintu Kereta Api, Pneumatik, Programmable Logic Controller (PLC), Sensor Proximity.}

\section{Penulis yang Berkaitan: \\ Wahyu Sapto Aji, Program Studi Teknik Elektro, Universitas Ahmad Dahlan, Kampus IV, Jl. Ring Road Selatan, Desa Tamanan, Kec. Banguntapan, Kab. Bantul, Yogyakarta 55166 \\ Surel: wahyusaji@gmail.com}

\begin{abstract}
ABSTRAK
Salah satu alternatif dalam mengurangi kecelakaan di pintu perlintasan kereta api tanpa penjaga adalah palang pintu kereta api pneumatik otomatis. Alat ini menggunakan PLC (Programmable Logic Controller) sebagai sistem pemroses. Palang pintu perlintasan kereta api otomatis bekerja dengan menggunakan dua buah sensor proximity yang di letakkan pada kanan dan kiri perlintasan dengan jarak yang jauh dari perlintasan (kurang lebih $1 \mathrm{KM}$ ). Keluaran sistem berupa aktifnya sirene, lampu, dan palang pintu yang digerakkan dengan pneumatik. Paling pintu ini akan bergerak naik dan turun menutup dan membuka perlintasan. Penggunaan pneumatik dalam pembuatan karena pneumatik lebih menghemat ruang sekitar perlintasan dan aman. Dalam pengujiannya, pendeteksian dilakukan dengan 2 arah yang berlawanan. Hasil menunjukkan alat telah bekerja menutup dan membuka perlintasan dengan kinerja yang baik.
\end{abstract}

One alternative in reducing accidents at railroad crossings without guards is automatic pneumatic railroad crossings. This tool uses PLC (Programmable Logic Controller) as a processing system. Automatic crossing railroad crossing works by using two proximity sensors that are placed on the right and left crossings with a distance far from the crossing (approximately $1 \mathrm{KM}$ ). The system outputs are pneumatically actuated sirens, lights and door lintels. At most this door will move up and down closing and opening the crossing. The use of pneumatics in manufacturing because pneumatics saves more space around the crossing and is safe. In testing, detection is done in 2 opposite directions. The results show the tool has been working to close and open crossings with good performance.

This work is licensed under a Creative Commons Attribution-Share Alike 4.0

\section{Sitasi Dokumen ini:}

A. Widodo, S. and W. S. Aji, "Palang Pintu Kereta Api Pneumatik Otomatis Berbasis PLC Omron CP1ENA20DR-A," Buletin Ilmiah Sarjana Teknik Elektro, vol. 1, no. 2, pp. 82--90, 2019. DOI: $\underline{10.12928 / \text { biste.v1i2.1011 }}$

\section{PENDAHULUAN}

Pengguna kendaraan dari tahun ke tahun semakin meningkat. Hal itu akan berdampak pada keadaan lalu lintas sehari-hari. Pengaruh baik maupun buruk dalam bertambah banyaknya pengguna lalu lintas mempengaruhi bagi kehidupan di lingkungan masyarakat apalagi di daerah yang sudah maju dan berkembang. Terbukti masih banyaknya indikasi angka kecelakaan yang disebabkan karena kelalaian.

Peristiwa transportasi yang sering terjadi di Indonesia salah satunya yaitu kecelakaan kereta api. Permasalahan sering terjadi pada pintu perlintasan kereta api. Kecelakaan tersebut disebabkan karena kelalaian petugas penjaga pintu atau pengemudi yang memiliki sikap tidak disiplin [1]. Selain disebabkan kelalaian petugas penjaga pintu, masih banyak dijumpai palang pintu kereta api yang tidak dijaga oleh petugas. Oleh 
karena itu, penelitian ini mengusulkan tentang palang pintu otomatis pada perlintasan kereta berbasis PLC (Programmable Logic Controller).

Penelitian sejenis mengusulkan tentang perancangan sistem otomatisasi palang pintu kereta api menggunakan metode deteksi kereta api sebagai bentuk objek bergerak dengan video processing menggunakan metode motion detection dan Transformasi Hough, sehingga terlihat keakuratan metode yang digunakan pada teknologi palang pintu kereta api otomatis. Tingkat akurasi maksimal dari jarak 60m dengan parameter Hough 50 dan luas pergeseran piksel 5000 dari sistem yang dapat mendeteksi objek kereta api [2].

Penelitian lainnya mengusulkan tentang implementasi kendali palang pintu kereta api menggunakan modul wireless NRF24L01 mengombinasikan beberapa IR sensor atau sensor infrared sebagai sistem kendali palang pintu kereta api secara otomatis dengan menghitung kendaraan dan kecepatan kereta sehingga menghasilkan sebuah output berupa keputusan pergerakan palang. Keputusan pergerakan palang diatur menggunakan logika fuzzy Sugeno yang nantinya menghasilkan pergerakan palang bergerak cepat, sedang atau lama. Pengujian dalam melakukan eksekusi program menghasilkan sebuah keputusan kurang dari batas waktu yang ditetapkan yaitu 61,2 detik sehingga hasilnya sesuai desain yang diinginkan dengan perbandingan error waktu sistem dengan waktu real time 4,6\% [3].

Penelitian lain membahas Control Room pada Sistem Palang Pintu Pencegah Kecelakaan Kereta Api dan Wifi Signal didesain menutup dari atas hingga bawah menyentuh jalan secara keseluruhan dengan ukuran panjang 3 meter dan tinggi 1 meter (sesuai lebar jalan). Dengan menutupi lebar jalan secara memanjang tanpa ada celah pengguna jalan untuk melintasi, palang pintu didesain seperti pisau dan bekerja secara otomatis dengan menggeser dari kanan ke kiri atau kiri ke kanan sehingga pengendara lebih waspada bahaya pada area rel [4].

Penelitian laiinya mengusulkan tentang Prototipe Palang Pintu Otomatis Pada Jalur Lintasan Kereta Api Berbasis Mikrokontroler dengan mendeteksi suara sirene kereta api menggunakan sensor suara, dua sensor cadangan apabila sensor suara gangguan yaitu dengan mendeteksi kedatangan kereta api dan mendeteksi jika kereta api telah melintasi palang pintu secara keseluruhan dengan menggunakan sensor inframerah [5].

Berdasarkan penelitian terdahulu yang telah dijelaskan, dapat dilakukan pengembangan sistem dengan membuat purwarupa Palang Pintu Kereta Api Pneumatik Otomatis Berbasis PLC OMRON CP1E-NA20DRA. Sistem tersebut menggunakan sensor proximity sebagai masukan sistem, sehingga alat ini akan bekerja secara otomatis saat mendeteksi kereta api datang.

\section{METODE PENELITIAN}

\subsection{Desain Sistem}

Penelitian ini diselesaikan dengan mengikuti beberapa proses, yaitu mendesain sistem, menentukan peralatan dan menganalisis hasil. Hal yang pertama kali yaitu mendesain sistem yang ditunjukkan pada Gambar 1.

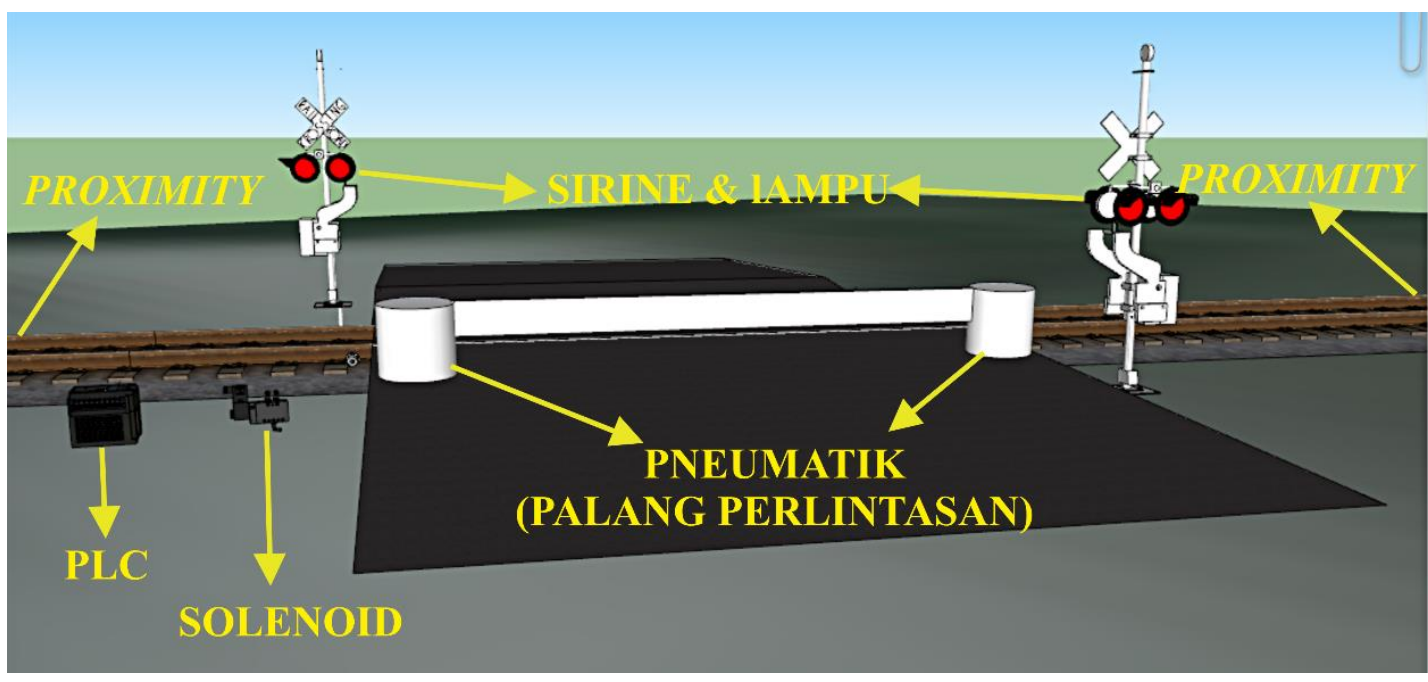

Gambar 1 Desain Palang Pintu Kereta Api Pneumatik Otomatis

Desain sistem pada Gambar 1, sistem palang pintu otomatis menggunakan dua buah sensor proximity (sensor jarak) induktif yang dipasang kanan dan kiri perlintasan sebagai masukan kemudian diproses oleh PLC dengan keluaran berupa gerak pneumatik, lampu dan sirene. PLC bekerja menerima data-data berupa sinyal peralatan input dari sensor proximity. Selanjutnya disimpan di dalam memory oleh CPU yang ada di dalam PLC sinyal digital [7]. 
Penelitian ini menggunakan sistem pneumatik sebagai aktuator yang bergerak dengan memanfaatkan tekanan angin yang bersumber dari kompresor untuk menghasilkan sistem penggerak pada palang pintu. Dengan menggunakan udara yang bersifat bersih dan kering menjadi keunggulan dalam menggunakan sistem pneumatik. Gesekan dapat diabaikan dan tidak terjadi kebocoran juga aman sehingga viskositas fluida lebih rendah [6].

Perangkat keras yang terdiri dari sensor sebagai masukan dan sirene, lampu, dan solenoid sebagai keluaran terhubung ke PLC. Diagram Pengkabelan perangkat keras ditunjukkan pada Gambar 2.

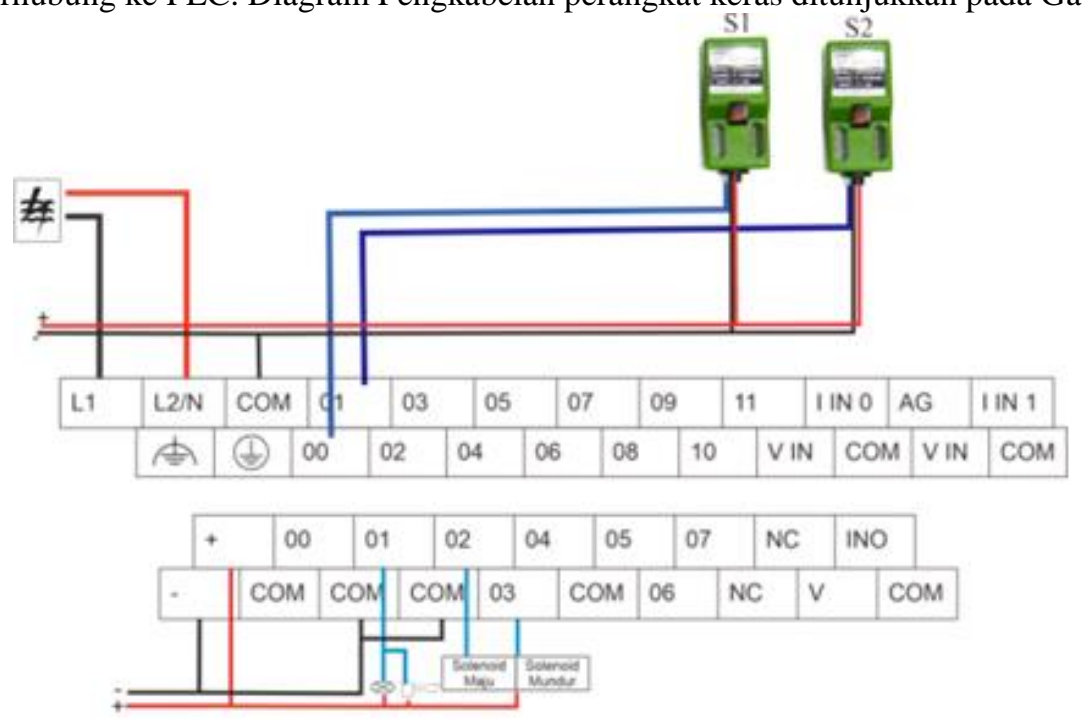

Gambar 2 Pengkabelan sistem

\subsection{Algoritme}

Algoritme sistem ditunjukkan pada Gambar 3, jika salah satu sensor mendeteksi kehadiran kereta api, maka alarm sirene dan lampu akan menyala. Selanjutnya palang pintu akan menutup dan palang pintu akan membuka ketika sensor yang lain mendeteksi kereta telah lewat.

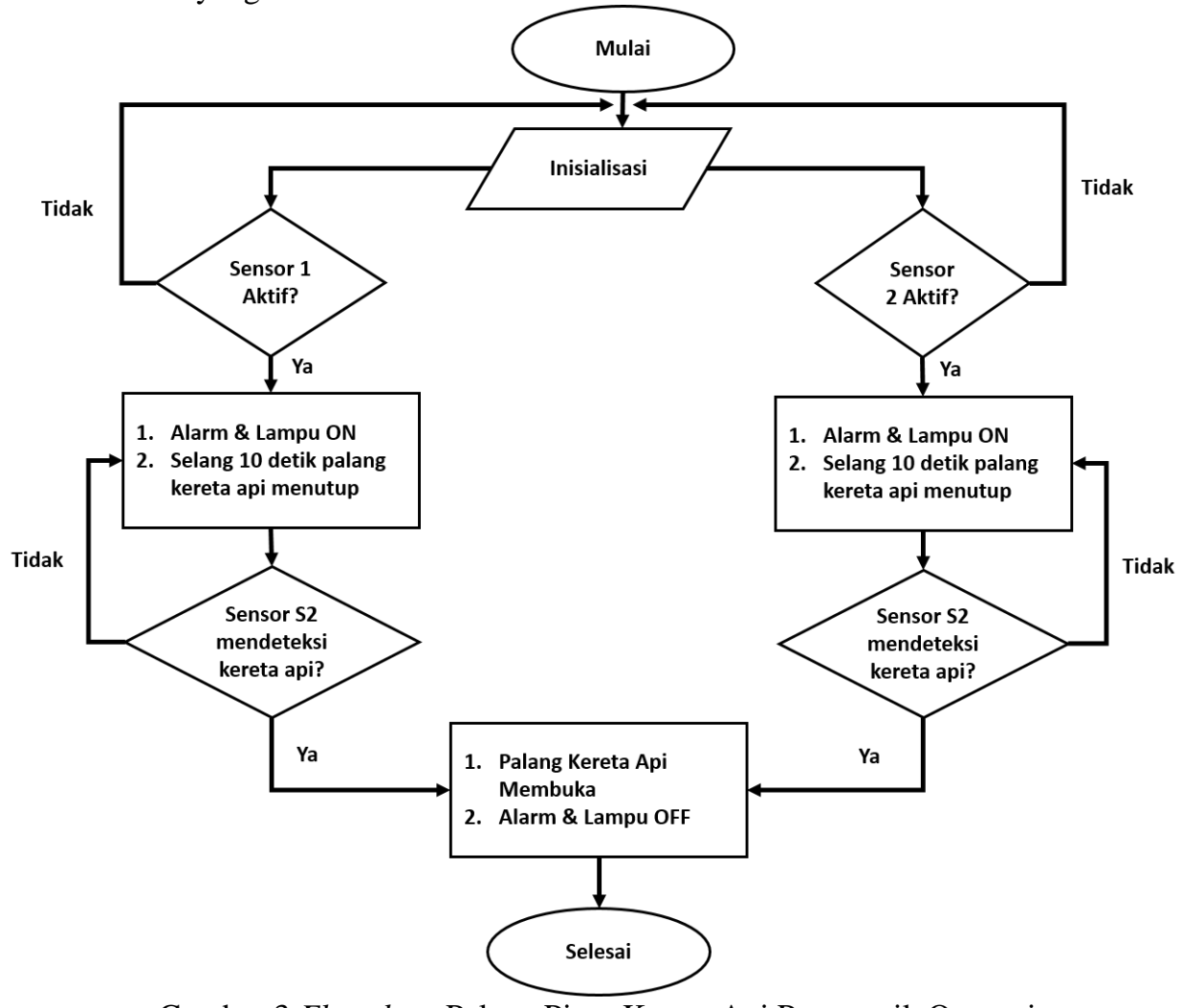

Gambar 3 Flowchart Palang Pintu Kereta Api Pneumatik Otomatis 
Setelah merancang algoritme sistem, langkah selanjutnya adalah merancang diagram state (diagram keadaan). Hasil desain diagram state ditunjukkan pada Gambar 4. Terdapat empat kondisi yang digunakan pada diagram state, yaitu kondisi $O F F$ (STA), lampu \& sirene (STB), solenoid maju (STC) dan solenoid mundur (STD). Kondisi T0 yaitu untuk memulai sistem, T1 yaitu sirene dan lampu akan aktif dari kondisi $O F F$ dengan mendeteksi pada salah satu sensor yang pertama, T2 akan mengaktifkan solenoid maju dengan menggunakan waktu setelah T1 bekerja, dilanjutkan dengan T5 yaitu setelah T2 bekerja selama 3 detik maka solenoid maju (T2) akan mati. Saat sensor kedua mendeteksi, maka T3 akan mengaktifkan solenoid mundur dengan waktu yaitu 3 detik, selanjutnya yaitu T4 dan T6 akan mati. Hasil perancangan diagram state tersebut diaplikasikan pada software CX-Programmer dalam bentuk program PLC yang ditunjukkan pada Gambar 8 .
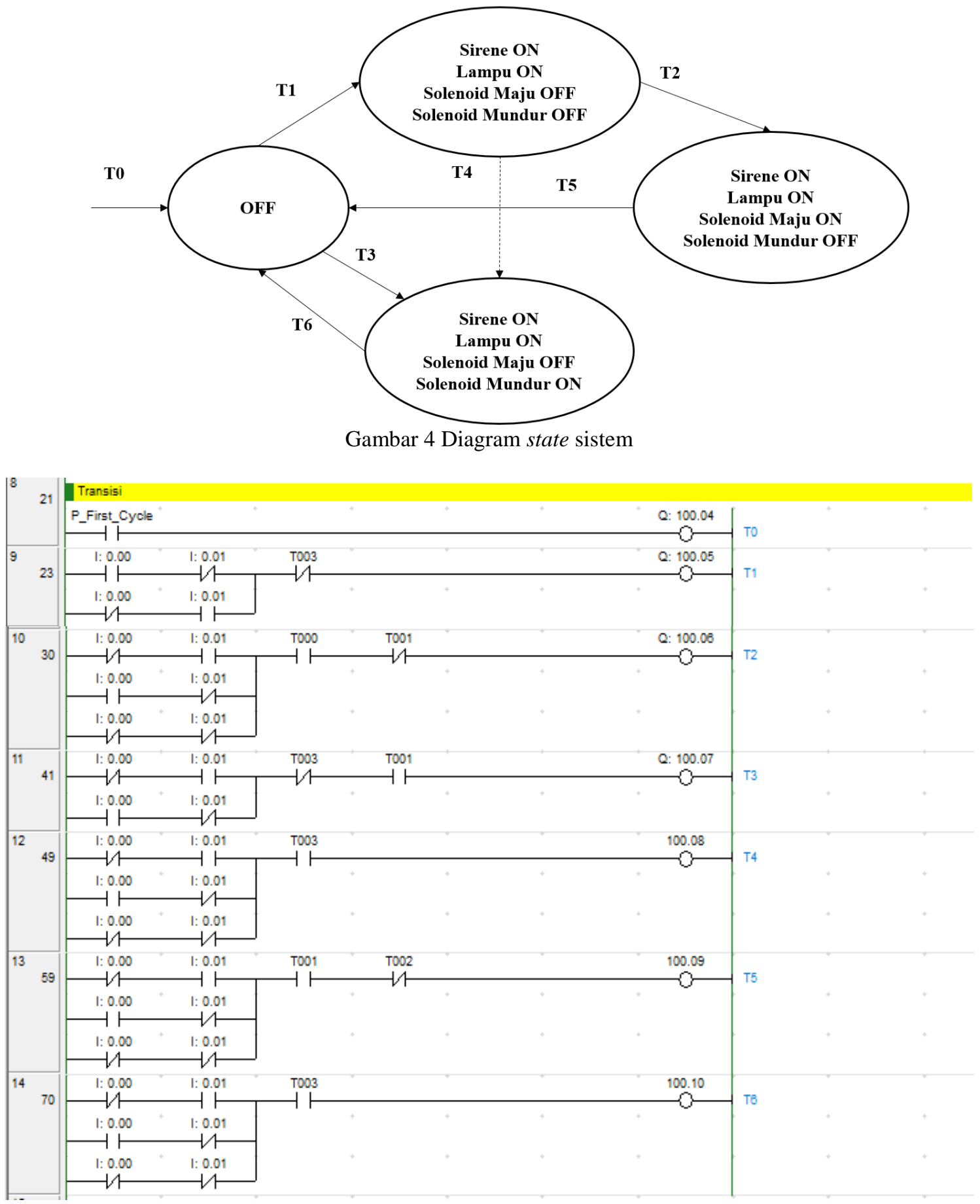

Gambar 5 (a) Program PLC 


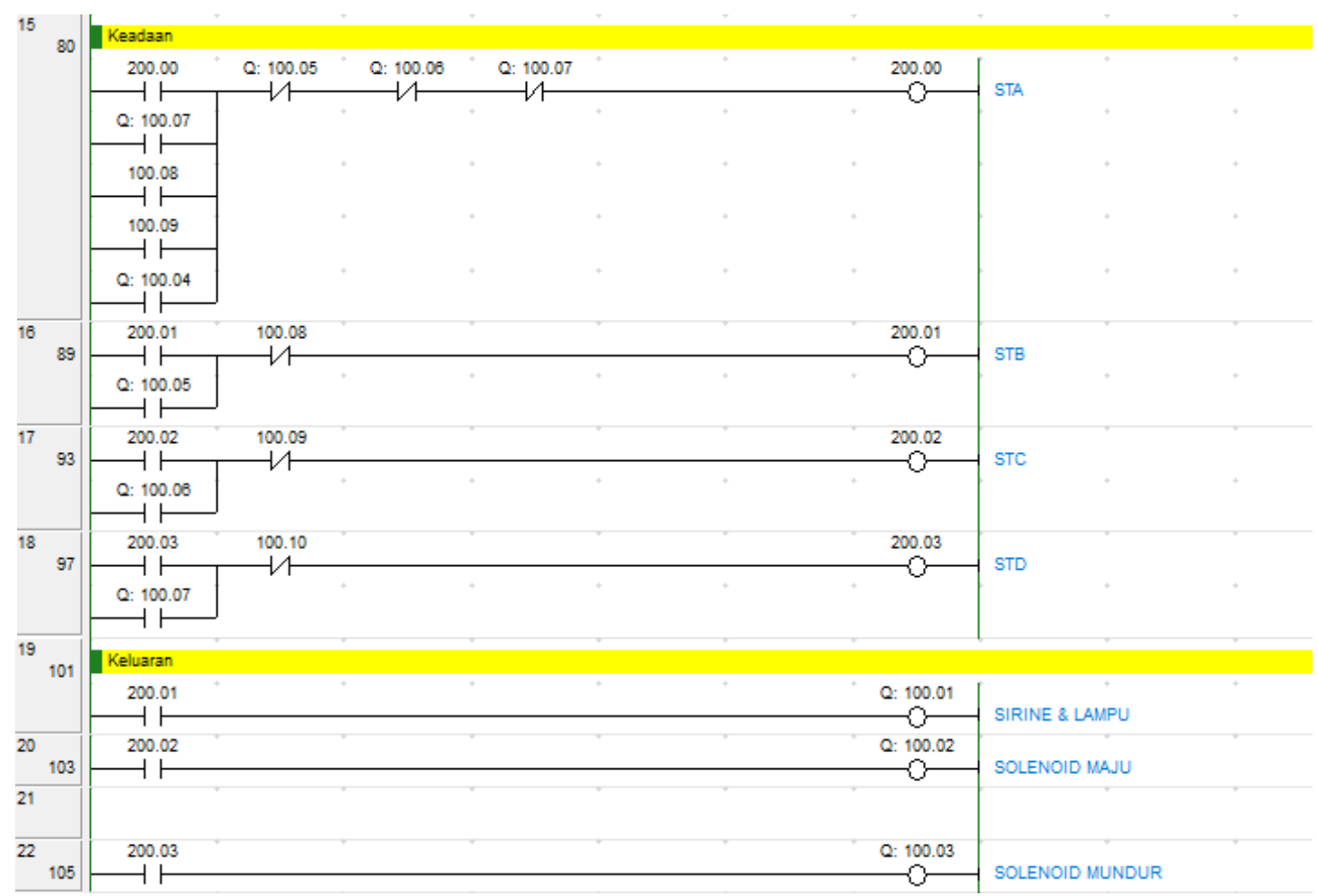

Gambar 5 (b) Program PLC

\subsection{Sistem Pneumatik}

Pneumatik bekerja dengan menggunakan tekanan udara sehingga dapat menggerakkan aktuator. Untuk menghasilkan kekuatan agar piston dapat bergerak secara linier (keluar - masuk), digunakan kekuatan udara bertekanan (yang terkompresi) pada aktuator [8]. Kontrol udara pada pneumatik dikendalikan melalui solenoid. Tekanan angin yang keluar dari kompresor dikendalikan oleh solenoid 5/3. Keluaran dari solenoid di cabangkan untuk menggerakkan aktuator sehingga aktuator akan bekerja maju atau mundur. Tenaga fluida yang berasal dari solenoid mewujudkan transfer daya pada aktuator berupa gerakan lurus atau gerakan putar [9]. Diagram dan rangkaian pneumatik menggunakan solenoid ditunjukkan pada Gambar 6.

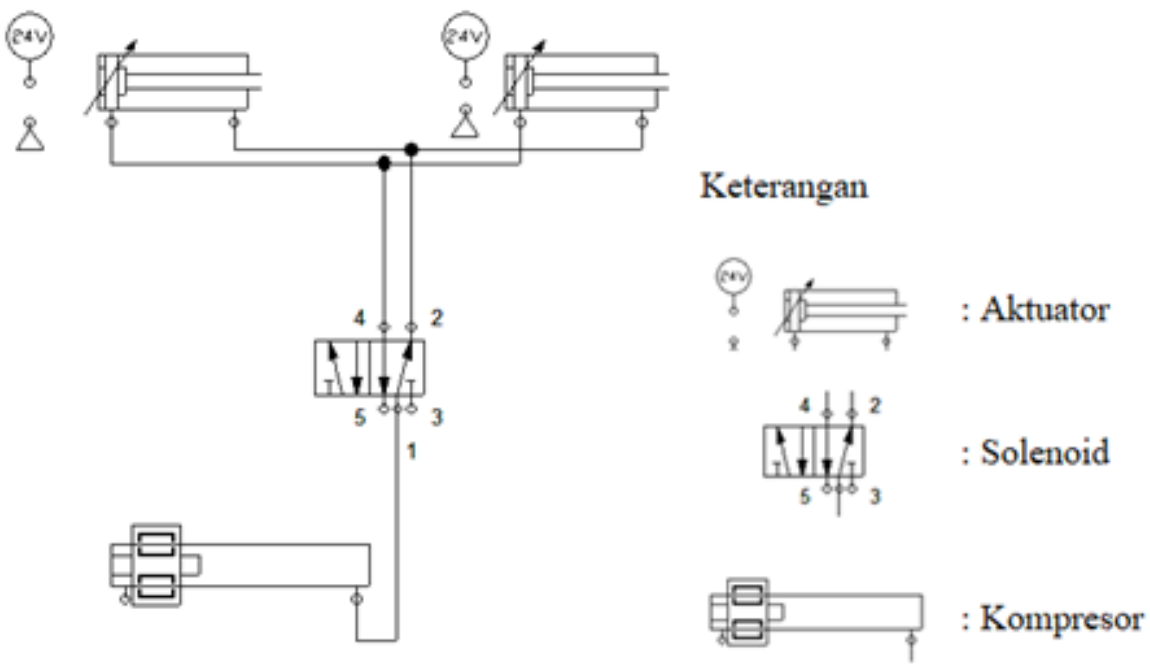

Gambar 6 Rangkaian pneumatik

Instalasi pemasangan pneumatik dengan selang ke solenoid ditunjukkan pada Gambar 7. Selang tersebut berfungsi untuk mengalirkan udara dari solenoid ke pneumatik. Selain itu juga digunakan untuk mengalirkan udara dari kompresor ke solenoid. 


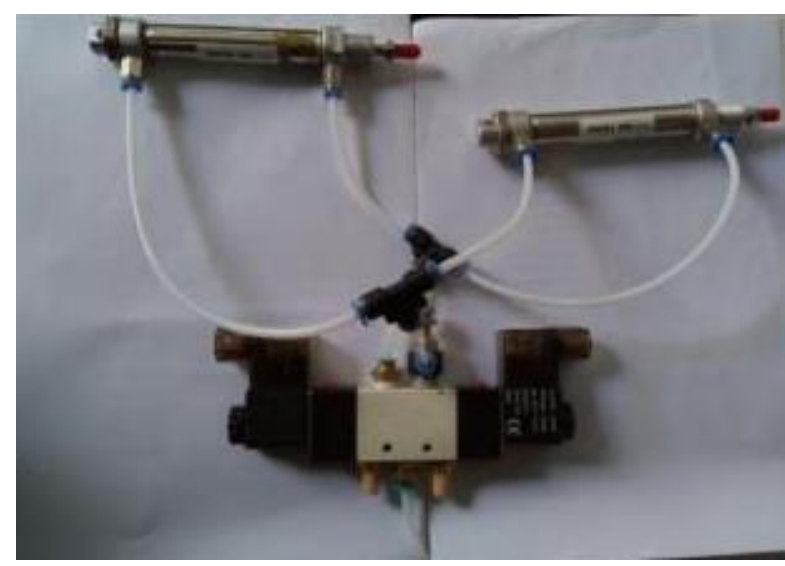

Gambar 7 Pemasangan aktuator ke solenoid

Tekanan dalam densitas udara mempengaruhi sistem pneumatik. Udara biasanya mempunyai kandungan air (H2O) sehingga untuk menentukan Densitas udara yang dihasilkan oleh filter udara untuk menjamin bekerjanya suatu sistem pneumatik yang tanpa terganggu dengan cara udara harus dalam keadaan kering sempurna, dapat dihitung sebagai berikut:

$$
\rho=\frac{p}{R T}
$$

Dengan $\rho$ adalah Densitas cahaya $\left(\mathrm{kg} / \mathrm{m}^{2}\right), \mathrm{P}$ adalah Tekanan $\left(\mathrm{N} / \mathrm{m}^{2}\right), \mathrm{R}$ adalah Konstanta gas $(\mathrm{J} / \mathrm{kg}), \mathrm{T}$ adalah Suhu (k).

Tekanan Hidrostatik dapat ditentukan dengan cara menghitung tekanan yang dilakukan dalam keadaan yang diam kemudian memiliki gaya tekanan yang diakibatkan massa jenis udara, gravitasi dan jarak terhadap titik acuan, maka dapat dihitung seperti berikut:

$$
P s=\rho . \mathrm{g} . \mathrm{H}
$$

dengan Ps adalah Tekanan hidrostatis $\left(\mathrm{N} / \mathrm{m}^{2}\right), \rho$ adalah Densitas cahaya $\left(\mathrm{kg} / \mathrm{m}^{2}\right)$, g adalah Percepatan gravitasi $\left(\mathrm{m} / \mathrm{s}^{2}\right)$, h adalah Jarak acuan $(\mathrm{m})$

Untuk menentukan tekanan yang dibutuhkan oleh tabung Double Acting Cylinder agar dapat melakukan penekanan stamp sehingga dapat mengecap dengan sempurna, dapat di hitung dengan persamaan sebagai berikut

$$
\begin{aligned}
& \mathrm{A}=\pi \cdot \mathrm{r}^{2} \\
& \mathrm{P}=\mathrm{F} / \mathrm{A} \\
& \mathrm{F}=\mathrm{P} . \mathrm{A}
\end{aligned}
$$

dengan $\mathrm{r}$ adalah jari-jari silinder $(\mathrm{m}), \mathrm{P}$ adalah Tekanan $\left(\mathrm{N} / \mathrm{m}^{2}\right)$, A adalah Luas Penampang $\left(\mathrm{m}^{2}\right), \mathrm{F}$ adalah Tekanan $(\mathrm{N})$.

\subsection{Pengujian Sistem}

Pengujian dilakukan dengan tiga bagian, yaitu pengujian sensor, pengujian program dan pengujian pneumatik. Pengujian sensor dilakukan dengan melakukan mendeteksi beberapa media yang sering dijumpai di sekitar kita seperti media berbahan besi, logam, aluminium, kayu, plastik dan karet. Dari media tersebut akan diketahui kesesuaian pendeteksian dengan bahan yang dipakai dalam pembuatan kereta api. Selanjutnya dilakukan pengujian terhadap jarak yang dapat terbaca oleh sensor.

Pengujian program yang sudah dituliskan di dalam software $C X$-Programmer akan dilakukan pengujian apakah program yang sudah dibuat ini sudah benar dan tidak terdapat error yang dapat mengganggu kinerja dari sistem. Setelah di lakukan tahapan pengujian sistem maka akan dilakukan pengujian pada pergerakan pneumatik yang dipengaruhi oleh sensor. Sensor akan menentukan apakah pintu pelintasan akan menutup atau membuka dan akan mengaktifkan atau menonaktifkan sirene lampu.

Pada pengujian akhir yaitu pengujian pneumatik yang sudah dihubungkan dengan PLC akan dilakukan pengujian apakah saat diberikan masukan (nilai 1) pada sensor, kontrol pneumatik akan bekerja menaikturunkan palang untuk menutup perlintasan. Selain hal itu, pengecekan kebocoran angin dilakukan agar alat bekerja secara maksimal. 


\section{HASIL DAN PEMBAHASAN}

\subsection{Pengujian Pneumatik}

Densitas Udara sempurna yang dihasilkan oleh filter udara untuk dapat bekerja pada suatu instalasi tanpa adanya masalah maka diharuskan keadaan udara yang tidak mengandung air atau paling tidak mempunyai kelembapan yang sedikit. Tekanan yang digunakan yaitu 4 Bar atau $4 \times 10^{5} \mathrm{~N} / \mathrm{m}^{2}$, ketentuan konstanta gas untuk udara kering sebesar $287(1 / \mathrm{kg})$ dan T adalah suhu 60C (suhu maksimal di manual book) atau 333 Kelvin.

$$
\rho=\frac{P}{R T}=\frac{4 \times 10^{\wedge} 5}{287 \times 333}=4,185 \mathrm{~kg} / \mathrm{m} 3
$$

Tekanan pada pneumatik:

$$
\begin{aligned}
P s & =\rho \cdot g \cdot \mathrm{H} \\
& =4,185 \cdot 9,81 \cdot 0,7 \\
& =28,74 \mathrm{~N}
\end{aligned}
$$

Tekanan pada double acting:

$$
\mathrm{F}=\mathrm{P} . \mathrm{A}
$$

dengan

$$
\begin{aligned}
\mathrm{A} & =\pi \cdot \mathrm{r}^{2} \\
& =3,14.0,03^{2} \\
& =2826 \times 10^{-3}
\end{aligned}
$$

Oleh karena itu,

$$
\begin{aligned}
\mathrm{F} & =\mathrm{P} \cdot \mathrm{A} \\
& =4 \times 10^{5} .2826 \times 10^{-3} \\
& =1.130 .400 \mathrm{~N}=11,3 \times 10^{5} \mathrm{~N}
\end{aligned}
$$

\subsection{Pengujian Sensor Proximity}

Sensor proximity (sensor jarak) digunakan untuk mendeteksi ada atau tidaknya suatu objek di depan sensor [10]. Pengujian sensor proximity induktif bertujuan untuk mengetahui jarak dan jenis benda yang dapat dideteksi oleh sensor. Media yang digunakan untuk menguji sistem kerja sensor yaitu media berbahan besi, logam, alumunium, kayu dan karet. Pemasangan sensor proximity ditunjukkan pada Gambar 8.

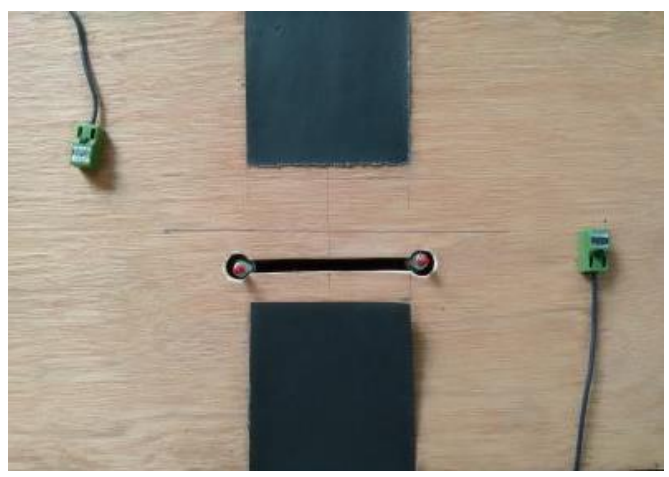

Gambar 8 Pemasangan Sensor

Hasil pengujian sensor proximity induktif ditampilkan pada Tabel 1. Pengujian dilakukan dengan menggunakan media dengan berbagai macam bahan seperti besi, logam, alumunium, kayu, karet dan plastik.

Tabel 1 Tabel pengujian deteksi berbagai media pada Sensor Proximity Induktif

\begin{tabular}{|c|c|c|}
\hline No & Jenis Media & Kondisi Deteksi \\
\hline 1 & Besi & Aktif \\
\hline 2 & Logam & Aktif \\
\hline 3 & Alumunium & Aktif \\
\hline 4 & Kayu & Tidak Aktif \\
\hline 5 & Karet & Tidak Aktif \\
\hline 6 & Plastik & Tidak Aktif \\
\hline
\end{tabular}


Berdasarkan hasil pengujian pada Tabel 1, dapat diketahui bahwa jenis bahan media yang terdeteksi oleh sensor adalah besi, logam dan alumunium. Karakteristik sensor proximity induktif hanya dapat membaca benda berupa besi, logam dan alumunium. Media tersebut digunakan dalam membuat kereta api sehingga sensor proximity induktif dapat mendeteksi jenis kereta api atau bukan yang melintasi sensor. Selain pengujian terhadap media tersebut, pengujian terhadap jarak media terhadap sensor diperlukan untuk mengetahui kemampuan sensor dalam mendeteksi. Pengujian jarak media terhadap sensor ditunjukkan pada Tabel 2.

Tabel 2 Tabel Pengujian Media terhadap Sensor

\begin{tabular}{|c|c|c|}
\hline No & Jarak media dengan sensor $(\mathbf{m m})$ & Kondisi Deteksi \\
\hline 1 & 0 & Terbaca \\
\hline 2 & 1 & Terbaca \\
\hline 3 & 2 & Terbaca \\
\hline 4 & 3 & Terbaca \\
\hline 5 & 4 & Tidak Terbaca \\
\hline 6 & 5 & Tidak Terbaca \\
\hline 7 & 6 & Tidak Terbaca \\
\hline 8 & 7 & Tidak Terbaca \\
\hline 9 & 8 & Tidak Terbaca \\
\hline 10 & 9 & Tidak Terbaca \\
\hline 11 & 10 & Tidak Terbaca \\
\hline
\end{tabular}

Jarak baca sensor hanya berkisar pada 0- $3 \mathrm{~mm}$, hal itu dikarenakan karakteristik sensor hanya dapat membaca 0-3 mm untuk sensor proximity induktif sehingga dalam penggunaannya pemasangan sensor harus dipasang sedekat mungkin dengan media yang akan dideteksi.

\subsection{Pengujian Sistem}

Pengujian sistem bertujuan untuk mengetahui alat telah berfungsi dengan baik atau masih ada kesalahan. Pengujian ini menggunakan dua arah asal yang berbeda, yaitu membaca S1 yang berakhir dengan S2 (kanan) dan S2 yang berakhir pada S1 (kiri). Hasil pengujian ditunjukkan pada Tabel 3.

Tabel 3 Tabel pengujian keberhasilan alat

\begin{tabular}{|c|c|c|c|c|c|c|}
\hline No & $\begin{array}{c}\text { Arah } \\
\text { kedatangan }\end{array}$ & Sensor & $\begin{array}{c}\text { Sirene dan } \\
\text { lampu }\end{array}$ & $\begin{array}{c}\text { Solenoid } \\
\text { maju }\end{array}$ & $\begin{array}{c}\text { Solenoid } \\
\text { mundur }\end{array}$ & Keterangan \\
\hline \multirow{2}{*}{1} & Kanan & S1 & v & v & - & Palang menutup \\
\cline { 3 - 7 } & & S2 & v & - & V & Palang membuka \\
\hline \multirow{2}{*}{2} & \multirow{2}{*}{ Kiri } & S2 & v & v & - & Palang menutup \\
\cline { 3 - 7 } & & S1 & v & - & v & Palang membuka \\
\hline \multirow{2}{*}{3} & \multirow{2}{*}{ Kiri } & S2 & v & v & - & Palang menutup \\
\cline { 3 - 7 } & & S1 & v & - & v & Palang membuka \\
\hline \multirow{2}{*}{4} & Kanan & S1 & v & v & - & Palang menutup \\
\cline { 3 - 7 } & & S2 & v & - & v & Palang membuka \\
\hline 5 & kanan & S1 & v & v & - & Palang menutup \\
\cline { 3 - 7 } & & S2 & v & - & V & Palang membuka \\
\hline
\end{tabular}

Berdasarkan hasil pengujian pada Tabel 3, dengan percobaan yang dilakukan sebanyak 5 kali diketahui bahwa alat berjalan secara umum dapat berjalan dengan baik. Alat dapat bekerja pada arah bolak-balik sehingga pengujian sistem berhasil dengan akurasi yaitu $100 \%$.

\section{KESIMPULAN}

Sistem palang pintu kereta api pneumatik bekerja dengan menggunakan dua buah sensor untuk mendeteksi kedatangan kereta api yang akan mengaktifkan sistem, sehingga palang menutup perlintasan dan akan membuka apabila kereta api sudah keluar dari jalur aman yang terdeteksi oleh sensor yang kedua. Purwarupa alat ini bekerja dengan akurasi yaitu $100 \%$ yang bekerja pada sensor proximity. Sensor hanya bekerja dengan mendeteksi benda dengan jarak 0-3 mm, sehingga untuk mendeteksi kereta harus sedekat mungkin dengan sensor. Untuk itu pengembangan alat ini diperlukan untuk memaksimalkan kerja pada saat pengaplikasian di lapangan. 


\section{UCAPAN TERIMA KASIH}

Saya ucapan terima kasih kepada editor dan reviewer atas segala saran, masukan dan telah membantu dalam proses penerbitan naskah. Ucapan terima kasih juga ditunjukkan kepada pihak-pihak yang telah mendukung penelitian dan memberikan bantuan moral dan material.

\section{REFERENSI}

[1] M. A. Firdaus, B. Utomo, J. T. Elektro, F. Teknik, And U. N. Semarang, "Miniatur Palang Pintu Kereta Api Otomatis Dengan Menampilkan Kecepatan Kereta Serta Waktu Tunggu Menggunakan Arduino,” Vol. 8, No. 1, 2016. Online

[2] M. Fayyadh, U. Sunarya, And R. Nugraha, "Perancangan Sistem Otomatisasi Palang Pintu Kereta Api Berbasis Motion Detection Automatic," Vol. 2, No. 1, Pp. 291-297, 2015. Online

[3] B. P. Pangestu, B. H. Prasetio, And G. E. Setyawan, "Implementasi Kendali Palang Pintu Kereta Api Menggunakan Ir Sensor,” Vol. 1, No. 4, Pp. 282-291, 2017. Online

[4] M. G. Putri, N. Fairusiyyah, And Y. Dharmawan, "Samurai PKK (Sistem Palang Pintu Pencegah Kecelakaan Kereta Api) Dengan Control Room Dan Wifi Signal,” Pp. 78-84. Online

[5] A. Ibrahim, "Prototype Palang Pintu Otomatis Pada Jalur Lintasan Kereta Api Berbasis Mikrokontroler," Pp. 9-10, 2015. Online

[6] S. Suryady Et Al., "Analisa Nilai Tekanan Proses Kerja Sistem Pneumatik Pada Mesin Pad Printing." Online

[7] T. S. P. Kusuma Dewi, "Aplikasi Programmable Logic Controller (Plc) Omron Cp1e Na20 Dra Dalam Proses Pengaturan Sistem Kerja Mesin Pembuat Pelet Ikan,” Vol. 17, No. 4, Pp. 170-177, 2014. doi: 10.14710/gt.v17i4.8937

[8] M. Subhan And A. Satmoko, "Penentuan Dimensi Dan Spesifikasi Silinder Pneumatik Untuk Pergerakan Tote Iradiator Gamma Multiguna Batan,” Vol. 10, No. 1978, Pp. 50-61, 2016. Online

[9] A. A. Akhmad, "Perancangan Simulasi Sistem Pergerakan Dengan Pengontrolan Pneumatik Untuk Mesin Pengamplas Kayu Otomatis,” Vol. 18, No. 3, Pp. 21-28, 2009. Online

[10] Ahmadi, M. Kamal, and Muhaimin, "Rancang Bangun Sistem Kendali Dan Monitor Pintu Perlintasan Kereta Api Secara Jarak Jauh,” Pp. 65-68. doi: 10.30811/litek.v13i2.1066

\section{BIOGRAFI PENULIS}

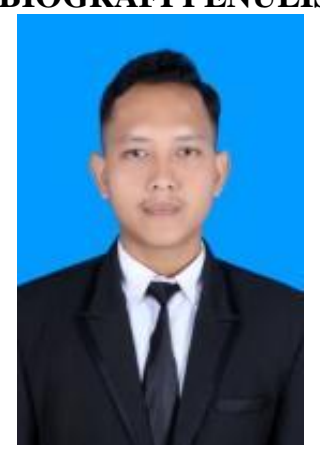

\section{Ari Widodo}

Penulis pertama adalah mahasiswa Program Studi Teknik Elektro, Universitas Ahmad Dahlan.

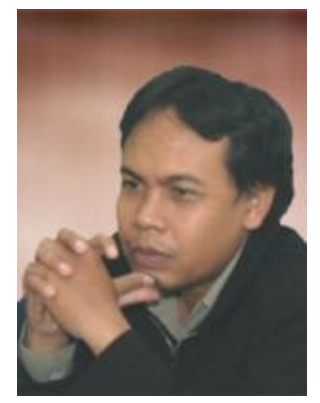

\section{Wahyu Sapto Aji}

Penulis kedua adalah Dosen di Program Studi Teknik Elektro, Universitas Ahmad Dahlan. 